\title{
Synchronous Aberrant Cerebellar and Opercular Development in Fetuses and Neonates with Congenital Heart Disease: Correlation with Early Communicative Neurodevelopmental Outcomes, Initial Experience
}
A. Wong, MSIII ${ }^{1}$
T. Chavez, MS²
S. O'Neil, $\mathrm{PhD}^{3}$
J. Votava-Smith, $\mathrm{MD}^{4}$
D. Miller, $M D^{7}$
S. delCastillo, $\mathrm{MD}^{5}$
A. Panigrahy, $\mathrm{MD}^{6}$
L. Paquette, $M D^{2}$

${ }^{1}$ New York Medical College, Valhalla, New York

2 Division of Neonatology, University Southern California, Children's Hospital Los Angeles Center for Fetal and Neonatal Medicine, Los Angeles, California

${ }^{3}$ Division of Neurology, University Southern California, Children's

Hospital Los Angeles, Los Angeles, California

${ }^{4}$ Division of Cardiology, University Southern California, Children's

Hospital Los Angeles, Los Angeles, California

${ }^{5}$ Division of Anesthesiology Critical Care Medicine, University Southern

California, Children's Hospital Los Angeles, Los Angeles, California

${ }^{6}$ Department of Radiology, University of Pittsburgh, Children's

Hospital of Pittsburgh of UPMC, Pittsburgh, Pennsylvania

7 Division of Obstetrics/Gynecology, University Southern California,

Children's Hospital Los Angeles Center for Fetal and Neonatal

Medicine, Los

Angeles, California

Am J Perinatol Rep 2017;7:e17-e27.
Address for correspondence Lisa Paquette, MD, Division of Neonatology, Children's Hospital Los Angeles, 4650 Sunset Blvd., MS\#31, Los Angeles, CA 90027 (e-mail: Ipaquette@chla.usc.edu).

\begin{abstract}
Keywords

- congenital heart disease

- fetus

- neonate

- brain growth

- neurodevelopment

- communication

Patients with congenital heart disease (CHD) demonstrate multidomain cognitive delays. Cingulo-opercular and cerebellar brain networks are critical to language functions. This is a description of our initial experience aiming to identify an anatomic correlate for CHD patients with expressive language delays. Fetal CHD patients, prospectively enrolled, underwent serial fetal (1.5T), postnatal pre- and postoperative (3T) MRI. Non-CHD patients were enrolled retrospectively from the same epoch. Comparable fetal and neonatal $\mathrm{T} 2$ contrast was used for manual linear cross-sectional measurement. Multivariable analysis was used for adjustments and curve fitting. Neurodevelopment was assessed with Battelle Developmental Inventory, 2nd ed. between 9 and 36 months of age. This interim analysis included patients from our longitudinal CHD study who had fetal, postnatal imaging and neurodevelopmental data-yielding a total of 62 mothers (11 CHD fetuses and 51 non-CHD fetuses). Altered brain trajectories were seen in selected cerebellar and opercular measurements in CHD patients compared with the non-CHD group. Smaller inferior cerebellar vermis measurements were associated with multiple communication-related abnormalities. Altered early structural development of the cerebellum and operculum is present in patients with CHD, which correlates with specific neurodevelopmental abnormalities.
\end{abstract}

received

September 22, 2016 accepted after revision November 3, 2016 
Despite the high survival rate of neonates undergoing cardiothoracic surgeries, many babies with congenital heart disease (CHD) grow up to have neurodevelopmental delays or disabilities later in life. When patients were assessed during school age, many had abnormal neurologic examinations, as well as gross and fine motor abnormalities. ${ }^{1,2}$ Ongoing research is exploring how neurodevelopmental outcomes in CHD patients may be related to differential growth and development of the brain during the fetal and neonatal period. One study found a structural neurodevelopmental delay of about 1 month in CHD fetuses, whereas another group described abnormalities of fetal brain growth and development using magnetic resonance imaging (MRI) volumetric analysis and MR spectroscopy.,

Preliminary unpublished results from our longitudinal study of brain development in fetuses, neonates, and children with CHD have demonstrated that children with CHD are at risk for having expressive language delays. This is supported by historical data in the literature. ${ }^{1,2,5,6}$ Although our preliminary results and prior reports have found this to be a pervasive finding for individuals with many different types of CHD (hypoplastic left heart syndrome, transposition of the great arteries, tetralogy of Fallot, isolated ventricular septal defect, etc.), the underlying pathogenic mechanisms have not yet been described. ${ }^{1,5,6}$ We embarked upon identifying neuroanatomical abnormalities that might be predictive of possessing such language delays. The two anatomic regions in the brain of particular interest are the operculum and cerebellum. These two regions have recently been demonstrated to share connectivity and cooperate in language coordination. Positron emission tomography (PET), MRI, and functional MRI (fMRI) demonstrate the intimate interplay between these regions during expressive language; additionally clinical correlates such as cerebellar mutism reveal how crucial these functions are to daily communication. ${ }^{7-11}$ Determining whether abnormalities exist in the very beginning and following the longitudinal brain trajectory of the children with CHD will help clarify developmental aberrations and optimize treatment plans.

The operculum includes areas of the brain essential to language and the motor components of speech, and is composed of portions from the frontal, temporal, and parietal lobes. $^{12,13}$ The development of the operculum begins when the fetus is approximately 20 weeks. ${ }^{14}$ At this time, the insular cortex is exposed. As growth of the frontal, temporal, and parietal lobes progresses, the opercular opening over the insular cortex decreases, resulting in closure of the operculum by the end of gestation. ${ }^{15}$ An open operculum and exposed insular cortex have been associated with neurodevelopmental delays and previously reported in neuroimaging studies of fetuses and neonates with CHD. 1,3,16,17

The cerebellum has long been accepted to play a crucial role in motor control, coordination, and balance. However, it is now being demonstrated to be involved in higher cognitive tasks such as learning and memory, attention, and language. ${ }^{13,18}$ Language processing tasks, such as word generation, verbal fluency, and semantic processing activate regions in the cerebellum. ${ }^{19}$ The cerebellar vermis is essential for gross motor synchronization and balance, and may be implicated in the speech deficits related to fine motor coordination loss in CHD patients. Past studies, using sonographic or MRI data, have characterized the growth of the cerebellar hemispheres and vermis during the fetal period. ${ }^{20-24}$ Studies have found differential cerebellar growth in small for gestational age fetuses and neonates, preterm infants, and fetuses with abnormal posterior fossae; however, cerebellar growth in fetuses with CHD has not been examined. ${ }^{18,25-27}$

In this report of our initial experience, we aim to describe the structural neurodevelopment of the operculum and cerebellum in CHD and non-CHD fetuses and neonates, using simple easily available biometrics obtained from serial fetal and neonatal MRI. The same imaging technique (single-shot fast spin echo [ssFSE]) was used to compare measurements across time points (fetal and neonatal) translatable without confusion. Additionally, we aim to determine whether there are any differences in the development of the operculum and cerebellum of CHD fetuses and neonates compared with control fetuses and neonates without CHD. We hypothesize that the internal opercular width will decrease before the external in normal controls, but both the internal and external opercular widths will remain larger in the CHD brains. Additionally, the cerebellar measurements will be smaller in the CHD individuals. Furthermore, we compare the neurodevelopmental scores with the anatomic measurements.

\section{Materials and Methods}

\section{Patients}

Pregnant mothers enrolled in the CHD cohort were approached for participation after having a clinically indicated fetal ECHO through the Institute for Maternal-Fetal Health. The non-CHD cohort comprised clinical and healthy controls. Clinical controls included fetuses that did not have a diagnosis of CHD but had other abnormalities including, but not limited to, suspected genitourinary, gastrointestinal, and limb abnormalities. The fetuses assigned as clinical controls were enrolled retrospectively once their clinically indicated fetal MRI was confirmed to have no central nervous system abnormality and their neonatal outcome was confirmed to have no neurologic concerns. The healthy controls, enrolled prospectively, were gravid women with uncomplicated pregnancies who volunteered to participate in this research project, including having fetal and postnatal MRIs of the brain and postnatal neurodevelopment evaluation. Only English and Spanish-speaking mothers were eligible. If, at the time of consent, there were confirmed fetal chromosomal abnormalities, suspected fetal structural brain malformation, suspected fetal infection, or maternal refusal or contraindication for MRI procedure, the patient was excluded. To be included in this analysis, a CHD fetus must have completed all imaging time points and have participated in the neurodevelopmental assessment.

From January 2011 to June 2015, a total of 64 mothers were enrolled in the study. There were 13 fetuses in the CHD cohort and 51 fetuses in the non-CHD cohort. Two of the mothers in the CHD group did not have a fetal MRI and were excluded from this study, making the final sample a total of 62 fetuses, 
with 11 CHD fetuses and 51 non-CHD fetuses. After enrollment, two CHD patients were identified to have a chromosomal abnormality and thus excluded.

\section{Magnetic Resonance Imaging}

Serial fetal (1.5T) and postnatal pre- and postoperative (3T) MRIs of the brain were completed in CHD patients. Comparable successive cross-sectional imaging was performed in the non-CHD patients no more than once during each the fetal and the neonatal periods, offering normal structural developmental models for which to relate the CHD data. Fetal MRI was performed on a $1.5 \mathrm{~T}$ system and the neonatal imaging on a 3T system (Philips) with a neonatal head coil and neonatal incubator (if clinically necessary). The following imaging sequences were acquired for fetal MRIs: an inclusion coil was placed over the mother's abdomen and multiple singleshot T2 fast-spin echo images were obtained using 3-mm thickness (0-mm gap) in at least two orthogonal planes with a repetition time (TR)/echo time (TE) of 120/12,500 milliseconds, one signal acquired, FOV_26-35 cm, a flip angle of 90 degrees, and a matrix of 196_195, 204_202, 112_92,272_172, section thickness 2-3 mm, spacing_0. For neonatal MRIs, the following imaging sequences were acquired: $\mathrm{T} 2$ in axial and sagittal planes (TE/TR_70/684-982 milliseconds, FOV_15-16 $\mathrm{cm}$, a flip angle of 90 degrees, matrix 120_98 or 112_92, section thickness, $3 \mathrm{~mm}$, spacing_0. No sedation was used for fetal or postnatal imaging unless clinically indicated by the discretion of the cardiothoracic intensive care team during the neonatal MRIs.

\section{Magnetic Resonance Imaging Brain Metrics}

Fetal ssFSE and neonatal T2 MR images were used for manual linear cross-sectional measurement post hoc. Gestational age was determined based on the most accurate overall assessment by the obstetrician and perinatologist. Brain structures were measured in three cross-sections as described by Garel. ${ }^{22}$ In the axial plane at the level of the operculum, the following were used as landmarks for the desired slice: the anterior horns and body of the lateral ventricles, third ventricle, and thalamus. Three measurements of the operculum were taken on the left and right side of the brain (-Fig. 1 ).

\section{Neurodevelopmental Assessment}

CHD patients returned when they were 9 to 36 months old for developmental evaluation with a pediatric neuropsychologist. Neurodevelopment was assessed in English or Spanish using the Battelle Developmental Inventory, 2nd ed.

\section{Statistical Analysis}

Wilcoxon-Mann-Whitney test was used to determine whether the estimated gestational age (EGA) populations mean rank differed among cohorts. Determining differences in brain measurements among cohorts were evaluated longitudinally with a repeated measures mixed-effects regression model. Mixed model random effect was at the patient level utilizing an identity covariance structure. Nonlinear (NL) mixed-effects growth models, accounting for repeated measurements, were fitted and assessed by maximum likelihood, Akaike information criterion corrected for small sample size (AICc), and Bayesian information criterion (BIC). In an effort to maintain the longitudinal aspects of the data, mixed effects were used as the "Independence" assumption of simple linear regression analysis did not hold. This type of generalized linear model provided for adjusting for gestational age whereas simple bivariate tests did not. Furthermore, this type of modeling also allows for handling of missing data. Spearman rho rank correlation with Bonferroni correction was used to correlate neurodevelopmental assessment scores with brain measurements in the fetal and postnatal pre- and postoperative periods. Multivariate and correlation analysis were adjusted for gestational age at the time of MRI scan. Missing data were handled with list-wise deletion in the correlation analysis; that is, all observations with missing values were excluded from the analysis to make all pairs identical and ensure a nonnegative definite correlation matrix. Statistical significance for Bonferroni corrected correlation analysis was set at $p<0.017$, and all other statistical significance were set at $p<0.05$. Regression models are presented as coefficient ( $95 \%$ confidence interval [CI]). Continuous variables are presented as mean \pm standard deviation (SD) or median (interquartile range [IQR]) as appropriate. Data analysis and graphics were produced using SAS (Statistical Software Package v 9.4, Cary, NC).

\section{Results}

\section{Clinical Characteristics of the Patient Cohorts}

Postmenstrual age (PMA) at birth of the entire fetal and neonatal cohort ranged from 19 to 38 weeks. The CHD cohort had an average PMA of 34 weeks at birth, whereas the nonCHD cohort had a PMA of 29 weeks at birth. There was a statistically significant difference in the PMA of each group $(p<0.01)$. The CHD cohort had six patients with hypoplastic left heart syndrome, two with transposition of the great arteries, two with pulmonary atresia with intact ventricular septum, one with each of the following: hypoplastic aortic arch, atrioventricular canal, and tetralogy of Fallot. In the nonCHD cohort, 35 were normal healthy controls, 8 were diagnosed with congenital pulmonary adenomatoid malformation, and 8 with congenital diaphragmatic hernia. There were no statistically significant differences between the left- and right-side brain measurements. Two of the $11 \mathrm{CHD}$ were identified postnatally to have 22q11.2 deletion (DiGeorge's syndrome). These were removed from the final analysis as this particular condition is known to have an impact on cerebellar and opercular growth, as well as neurodevelopment. $^{28-30}$ (Interestingly, the opercular abnormalities are more pronounced in the fetal and preoperative period if the 22q11.2 patients are included, [-Appendix]. This is consistent with the literature. ${ }^{28}$ ) The following were omitted in the operculum data as precise images were not available: right operculum for one CHD fetus and seven non-CHD fetuses and left operculum for three non-CHD fetuses. Clear measurement of the floor of the fourth ventricle was not obtainable in the images of two non-CHD fetuses. 


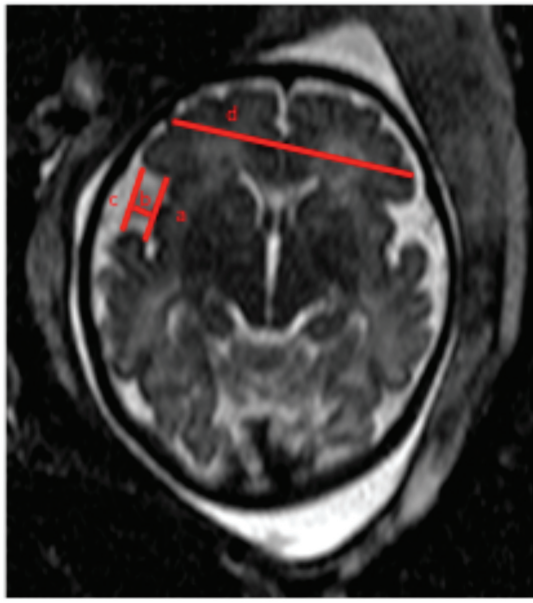

A Fetal CHD 36wks

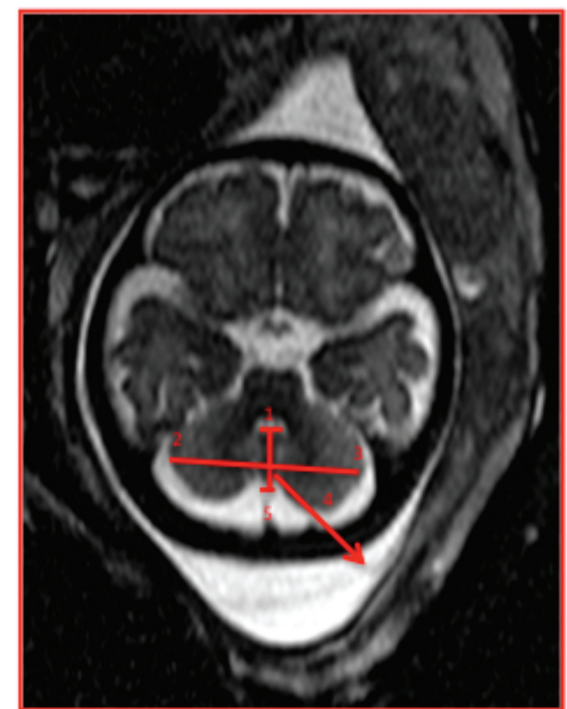

B

Fetal CHD 36wks

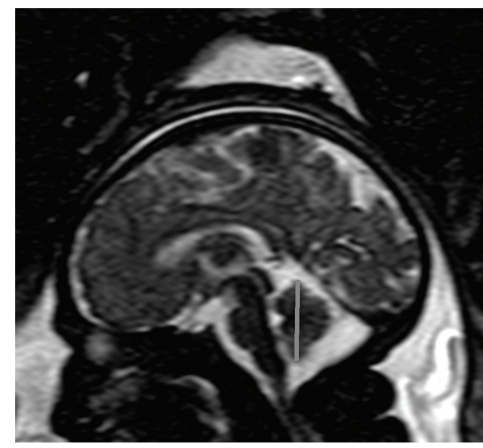

Fetal CHD 36wks a: Opercular Inside Opening

b: Opercular Length

c: Opercular Outside Opening

d: Biparietal Brain Diameter

1: Floor of 4 th Ventricle Width 2: Transverse Diameter Cerebellar Left Hemisphere 3: Transverse Diameter Cerebellar Right Hemisphere 4: Vermis Length

5: Inferior Vermis Width

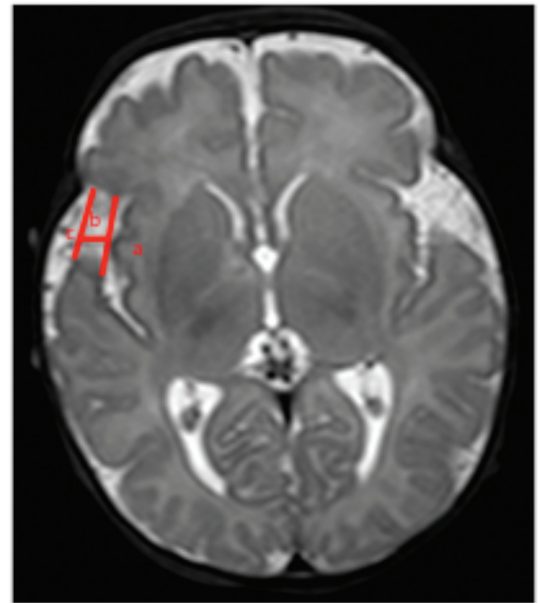

Neonatal CHD 39wks

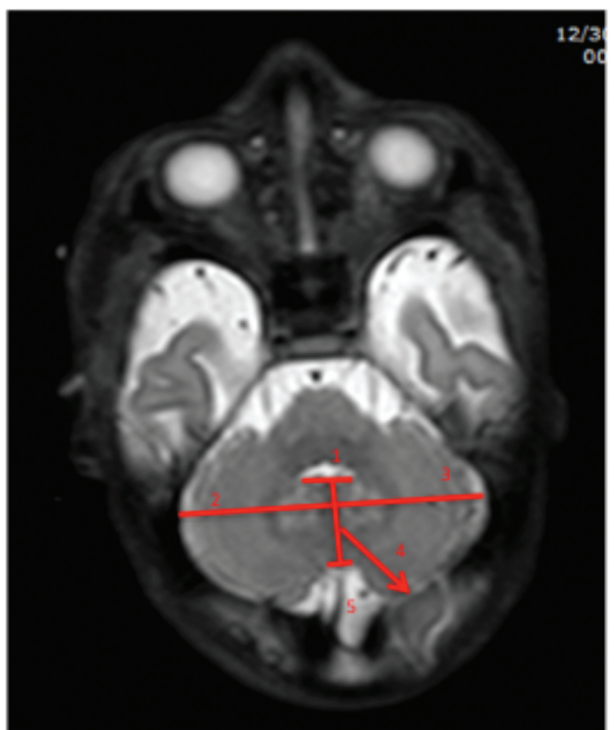

Neonatal CHD 39wks

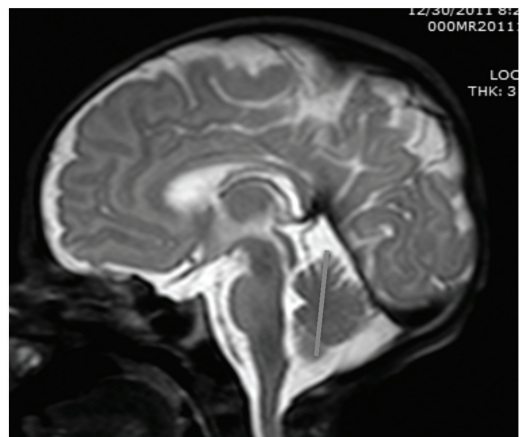

Neonatal CHD 39wks

Fig. 1 (A) Operculum measurements, axial section measurements from same patients at fetal and neonatal time points. (B) Cerebellum measurements, axial section measurements from same patients at fetal and neonatal time points. (C) Cerebellar vermis, sagittal measurements from same patients at fetal and neonatal time points. CHD, congenital heart disease.

\section{Comparison of Brain Metrics Measurements between CHD and non-CHD Cohorts}

For fetuses and neonates with CHD, there was evidence of delayed internal closure of bilateral opercula compared with normal controls. Also, there was bilateral lateral ventricle enlargement in the CHD cohort. Additionally, cerebellar sagittal vermis height was significantly smaller in the CHD fetuses and neonates. Measurements done to demonstrate whether significant overall cerebral atrophy existed were normal in the CHD group (nonsignificant differences between the CHD and control groups in brain biparietal or bone biparietal diameters) (-Fig. 2, - Table 1). 

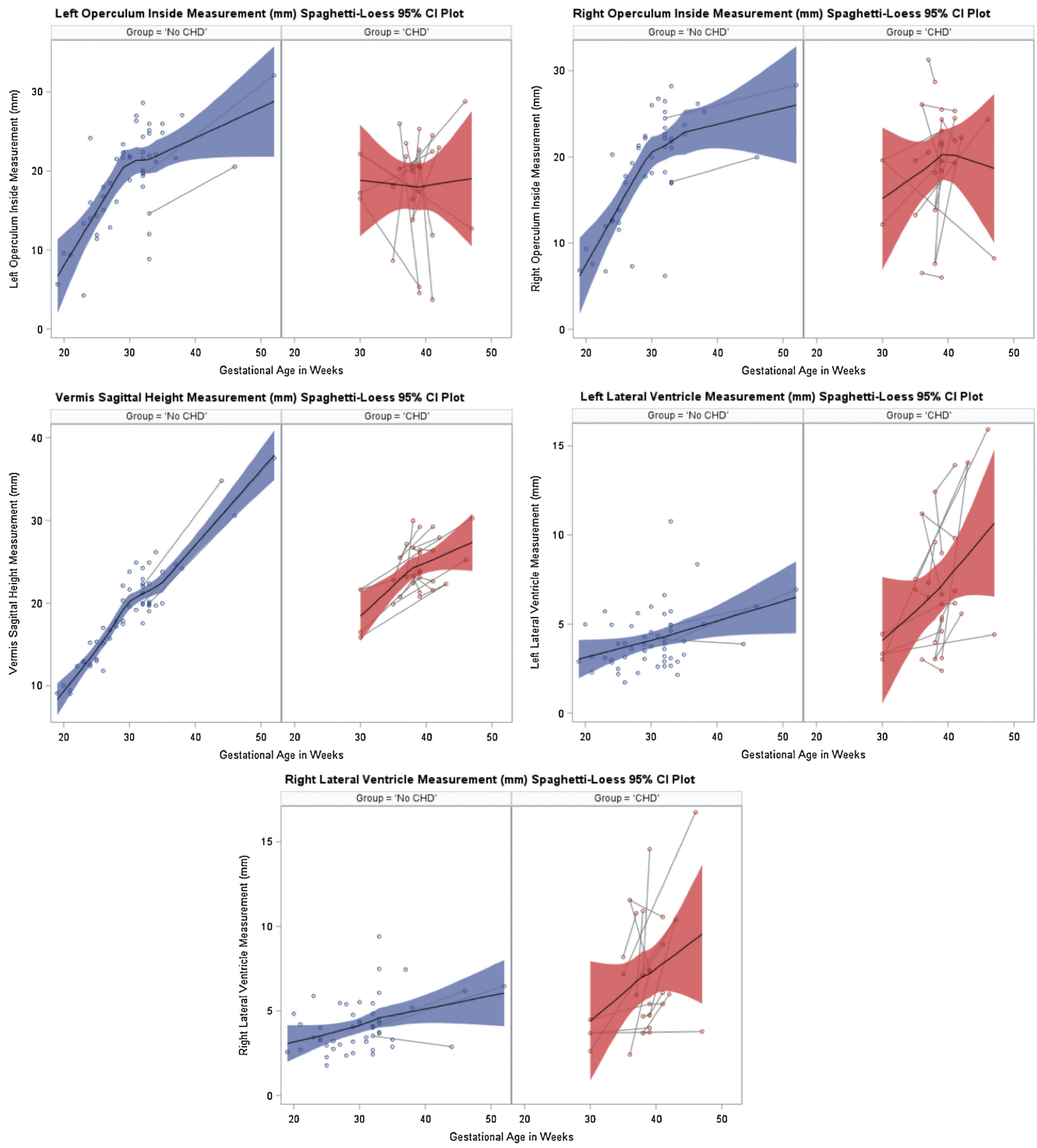

Fig. 2 Growth curves of significant differences between congenital heart disease (CHD) and controls. Cl, confidence interval.

\section{Growth Curve Characteristics for Patient Cohorts}

For CHD fetuses and neonates, mixed linear growth curves best describe the measurements focused on in this study (opercular and ventricle), with the exception of the vermis where NL logistic and Gompertz growth curves fitted best. In contrast, normal healthy control fetus and neonate brain measurements were best described with NL logistic growth curves. The NL logistic and the Gompertz curves are both sigmoid curves used to fit brain measurement growth across gestational ages. Initial growth of these functions is approximately exponential, but unlike an exponential curve that continues to rise, the growth slows into an s-shaped curve (-Table 2).

\section{Correlation with Neurodevelopmental Outcomes}

When comparing the neurodevelopmental scores with the anatomic measurements, the cerebellar inferior vermis width was significantly negatively correlated with expressive communication in the CHD cohort. Decreases in scores of the adaptive developmental quotient correlated with smaller measurements of the left cerebellar hemisphere. Additionally, the cerebellar inferior vermis width was smaller and 
22 Synchronous Aberrant Cerebellar and Opercular Development Wong et al.

Table 1 Brain measurements in CHD cohort compared to non-CHD cohorts

\begin{tabular}{|l|l|l|l|}
\hline Measurement (mm) & CHD $\beta$ & $95 \% \mathrm{Cl}$ & $p$ \\
\hline Operculum inside left & -5.39 & $-8.66,-2.11$ & $<0.01$ \\
\hline Operculum inside right & -4.32 & $-7.78,-0.85$ & 0.02 \\
\hline Operculum outside left & -1.50 & $-4.62,1.62$ & 0.34 \\
\hline Operculum outside right & -1.12 & $-4.22,1.98$ & 0.47 \\
\hline Operculum length left & 0.62 & $-0.44,1.68$ & 0.24 \\
\hline Operculum length right & -0.03 & $-0.89,0.84$ & 0.95 \\
\hline Cerebellum floor 4th ventricle & 0.81 & $-0.53,2.15$ & 0.23 \\
\hline Cerebellum inferior vermis & -0.52 & $-1.42,0.38$ & 0.25 \\
\hline Vermis height axial & 0.27 & $-1.00,1.54$ & 0.67 \\
\hline Cerebellar hemisphere left & 0.08 & $-0.87,1.03$ & 0.87 \\
\hline Cerebellar hemisphere right & -0.29 & $-1.38,0.80$ & 0.59 \\
\hline Vermis height sagittal & -1.94 & $-3.37,-0.52$ & 0.01 \\
\hline Brain biparietal diameter & -1.98 & $-5.27,1.32$ & 0.23 \\
\hline Bone biparietal diameter & -1.03 & $-4.72,2.66$ & 0.58 \\
\hline Lateral ventricle left & 1.58 & $0.19,2.97$ & 0.03 \\
\hline Lateral ventricle right & 1.75 & $0.032,0.24$ & 0.01 \\
\hline
\end{tabular}

Abbreviations: $\mathrm{CHD}$, congenital heart disease; $\mathrm{Cl}$, confidence interval.

CHD- $\beta$ slope compares to non-CHD babies' growth pattern. For example, for left operculum inside width, after adjusting for gestational age at time of MRI, CHD patients' left operculum inside width was $5.39 \mathrm{~mm}$ smaller compared to non-CHD patients $(p<0.01)$.

$p$ is based on an analysis of mixed-effects repeated measures adjusting for gestational age at time of MRI, and patient's between-subject and withinsubject error.

predicted a decrease in scores in the communication, cognitive, personal-social and total developmental quotients (-Table 3).

\section{Discussion}

This study is one of the first to demonstrate that the neonatal CHD language-communication structures in the brain follow an abnormal trajectory and these aberrations correlate with several domains of neurodevelopmental skills.

\section{Operculum}

There have been previous demonstrations on MRI preoperatively in a variety of CHD lesions of the existence of open opercula with an approximate $17 \%$ incidence. ${ }^{3,31}$ Additionally, autopsy data of hypoplastic left heart neonates found delayed opercularization. ${ }^{32}$ Cortical maldevelopment has been demonstrated in this population as well. ${ }^{33-35}$ Interestingly, one study of 18 hypoplastic left heart fetuses and 30 control fetuses (25-37 weeks' gestation at MRI) demonstrated no significant difference in opercular development between the two groups except for less asymmetry between the two sides in the CHD group. ${ }^{35}$ Having no difference between left and right coincides with our data and may be a reflection of altered or decreased brain differentiation or specialization in the CHD population. Although we observed a significant delay in the closure of the CHD operculum, it was surprising that the presence of this anatomic deviation did not correlate with any neurodevelopmental deficiencies. Perhaps with a larger sample size, an effect may be visible.

\section{Cerebellum}

More than $70 \%$ of all the human brain neurons are found in the cerebellum, and for many years, the cerebellum was considered to simply be involved in movement and coordination. ${ }^{7,36}$ More recently, the cerebellum is being recognized to have many more important roles. Neuroanatomical, imaging, and clinical correlates have provided evidence that nonmotor language and cognitive functions also reside in the cerebellum, where critical temporal orchestration may occur. $^{7,36,37}$ It is now known that fibers traversing through the thalamus, the pontine nuclei, the red nucleus, and/or the inferior olive connect the prefrontal cortex to the languagedominant opercular region and cerebellum. ${ }^{7}$ Clinical and imaging correlations suggest that the vermis is also involved in language processing. $7,37,38$

A condition referred to as cerebellar mutism syndrome occurs most commonly after a child has surgery for a tumor in the posterior fossa. The condition results in temporary loss of speech ( 4 days to 5 months). ${ }^{10,37,39}$ Interestingly, the vermis has been a focus of prevention strategies for protecting from cerebellar mutism as this specific structure is thought to play a role in speech initiation..$^{10,39}$ Puget et al have demonstrated that the more extensive damage observed to the inferior vermis correlates with the greater deficits. ${ }^{40}$ 
Table 2 Growth curve analysis among cohorts

\begin{tabular}{|c|c|c|c|c|c|c|}
\hline & \multicolumn{3}{|l|}{ No CHD } & \multicolumn{3}{|l|}{ CHD } \\
\hline & -2 Log likelihood & AICc & $\mathrm{BIC}$ & -2 Log likelihood & AICc & BIC \\
\hline \multicolumn{7}{|l|}{ Operculum inside left } \\
\hline Mixed linear & 294.5 & 296.6 & 298.5 & 182.0 & 184.1 & 184.4 \\
\hline NL logistic growth curve & 257.6 & 269.0 & 277.0 & 183.8 & 196.5 & 195.8 \\
\hline NL Gompertz growth curve & 492.6 & 504.0 & 512.0 & 184.2 & 196.9 & 196.2 \\
\hline \multicolumn{7}{|l|}{ Operculum inside right } \\
\hline Mixed linear & 272.8 & 274.9 & 276.7 & 176.4 & 178.6 & 178.8 \\
\hline NL logistic growth curve & 248.6 & 260.1 & 267.5 & 177.3 & 190.2 & 189.3 \\
\hline NL Gompertz growth curve & 275.2 & 286.7 & 294.1 & 266.2 & 279.1 & 278.2 \\
\hline \multicolumn{7}{|l|}{ Vermis height sagittal } \\
\hline Mixed linear & 236.5 & 238.6 & 240.5 & 144.4 & 146.6 & 146.8 \\
\hline NL logistic growth curve & 218.9 & 230.2 & 238.6 & 131.0 & 143.6 & 143.0 \\
\hline NL Gompertz growth curve & 236.3 & 247.5 & 256.0 & 130.9 & 143.5 & 142.9 \\
\hline \multicolumn{7}{|l|}{ Lateral ventricle left } \\
\hline Mixed linear & 198.0 & 200.0 & 201.9 & 152.2 & 154.4 & 154.6 \\
\hline NL logistic growth curve & 187.9 & 199.2 & 207.4 & 142.5 & 155.1 & 154.5 \\
\hline NL Gompertz growth curve & 302.7 & 314.0 & 322.1 & 201.7 & 214.3 & 213.7 \\
\hline \multicolumn{7}{|l|}{ Lateral ventricle right } \\
\hline Mixed linear & 179.6 & 181.6 & 183.5 & 151.9 & 154.0 & 154.3 \\
\hline NL logistic growth curve & 169.4 & 180.8 & 188.5 & 143.7 & 156.3 & 155.7 \\
\hline NL Gompertz growth curve & 284.8 & 296.2 & 303.9 & 143.8 & 156.4 & 155.8 \\
\hline
\end{tabular}

Abbreviations: AICc, Akaike's information criteria; BIC, Schwarz's Bayesian information criteria (the lower the score, the better the curve fit). Linear Mixed Effects $Y=U_{i}+\beta_{1}+\beta_{2} t_{j}+\varepsilon_{i j}$ Non Linear Logistic Growth Curve $\quad Y=\frac{\beta_{1}}{\left(1+e^{\left.\beta_{2}-\beta_{3} t\right)}\right.}$

Non Linear Gompertz Growth Curve $\quad Y=\beta_{1} e^{-e^{\beta_{2}-\beta_{3} t}}$

Rows with the lowest values have been italicized.

Our study as well as a prior study demonstrated cerebellar vermian growth deficiencies in fetuses with CHD. ${ }^{41}$ Additionally, this study contributed neonatal findings as well as neurodevelopmental correlation. Continued study of this region and its impact on language and cognitive functions will help clarify whether the caudocranial fiber development has gone awry or the descending control mechanisms have maldeveloped.

\section{Growth Curves}

To our knowledge, this is the first study, although preliminary, to compare longitudinal brain growth of certain structures of fetuses and neonates with CHD to normally growing fetuses and neonates. There were significant differences demonstrated not only in the measurements but also in the overall growth patterns that described their trajectories. This is a unique vantage point of the impact that an abnormally developing heart can have on brain development over an extended amount of time. Borzage et al developed a growth curve from previously modified equations that would describe brain growth throughout a lifetime. ${ }^{42}$ Although we did not measure overall brain growth, the normal healthy control measurements plotted on growth curves seemed to follow this general pattern.

The opercular growth deficiency was as predicted in the CHD population. Unfortunately, there has not been a description of the opercular development in fetuses and neonates who have CHD nor a previously dedicated growth curve for normal opercular growth. There have been studies describing opercular growth in healthy neonates. These have demonstrated differences between the right and left sides of the brain as well as an impact that sex has on opercular development. ${ }^{43,44}$ Our study for neither the CHD nor the normal healthy controls found a right-versus left-side difference. This may have been due to our smaller sample size. Our sample size also limited us in breaking down the population further into male versus female to look for gender effect.

The ventricular size of the fetus and neonate in normal healthy individuals has been described on growth curves that have a relatively linear appearance from 25 to 35 weeks of gestation. ${ }^{45}$ Our normal healthy controls fall onto a growth curve that is very similar.

The cerebellar vermis measurements having been significantly different on one view (vermis sagittal height) provides 
Table 3 Correlation of brain measurements and Battelle scores, significant scores only

\begin{tabular}{|c|c|c|c|c|c|c|c|c|c|}
\hline \multirow[t]{2}{*}{ Score (correlation, $p$ value) } & \multicolumn{4}{|l|}{ Fetal } & \multicolumn{3}{|l|}{ Preoperative } & \multicolumn{2}{|l|}{ Postoperative } \\
\hline & $\begin{array}{l}\text { Left cerebellar } \\
\text { hemisphere }\end{array}$ & $\begin{array}{l}\text { Brain } \\
\text { biparietal } \\
\text { diameter }\end{array}$ & $\begin{array}{l}\text { Bone } \\
\text { biparietal } \\
\text { diameter }\end{array}$ & $\begin{array}{l}\text { Right } \\
\text { ventricle }\end{array}$ & $\begin{array}{l}\text { Right } \\
\text { cerebellar } \\
\text { hemisphere }\end{array}$ & $\begin{array}{l}\text { Brain } \\
\text { biparietal } \\
\text { diameter }\end{array}$ & $\begin{array}{l}\text { Left } \\
\text { ventricle }\end{array}$ & $\begin{array}{l}\text { Cerebellum floor } \\
\text { 4th ventricle }\end{array}$ & $\begin{array}{l}\text { Cerebellum } \\
\text { inferior vermis width }\end{array}$ \\
\hline \multirow[t]{2}{*}{ Self-care } & -0.69 & -0.64 & -0.71 & -0.78 & -0.08 & -0.86 & -0.54 & 0.45 & -0.77 \\
\hline & 0.06 & 0.08 & 0.05 & 0.02 & 0.86 & 0.01 & 0.21 & 0.37 & 0.07 \\
\hline \multirow[t]{2}{*}{ Self-concept and social role } & 0.44 & -0.65 & -0.93 & -0.83 & -0.34 & -0.51 & -0.21 & 0.09 & -0.83 \\
\hline & 0.28 & 0.08 & $<0.01$ & 0.01 & 0.46 & 0.24 & 0.65 & 0.86 & 0.04 \\
\hline \multirow[t]{2}{*}{ Expressive communication } & -0.52 & -0.57 & -0.60 & -0.77 & 0.09 & -0.51 & -0.18 & 0.21 & -0.92 \\
\hline & 0.18 & 0.14 & 0.12 & 0.02 & 0.84 & 0.24 & 0.70 & 0.69 & $<0.01$ \\
\hline \multirow[t]{2}{*}{ Fine motor } & -0.49 & 0.04 & 0.13 & -0.05 & 0.95 & 0.02 & 0.62 & 0.77 & -0.23 \\
\hline & 0.22 & 0.93 & 0.75 & 0.91 & $<0.01$ & 0.97 & 0.14 & 0.07 & 0.67 \\
\hline \multirow[t]{2}{*}{ Attention and memory } & -0.42 & -0.56 & -0.79 & 0.60 & -0.37 & -0.34 & -0.71 & -0.21 & -0.88 \\
\hline & 0.30 & 0.15 & 0.02 & 0.11 & 0.42 & 0.46 & 0.08 & 0.69 & 0.02 \\
\hline \multirow{2}{*}{$\begin{array}{l}\text { Adaptive developmental } \\
\text { quotient }\end{array}$} & -0.81 & -0.69 & -0.68 & -0.69 & -0.06 & -0.86 & -0.59 & 0.44 & -0.80 \\
\hline & 0.02 & 0.06 & 0.06 & 0.06 & 0.89 & 0.01 & 0.16 & 0.38 & 0.06 \\
\hline \multirow{2}{*}{$\begin{array}{c}\text { Personal-social } \\
\text { developmental quotient }\end{array}$} & -0.51 & -0.63 & -0.82 & -0.80 & -0.16 & -0.49 & -0.34 & 0.06 & -0.93 \\
\hline & 0.20 & 0.10 & 0.01 & 0.02 & 0.74 & 0.26 & 0.46 & 0.90 & $<0.01$ \\
\hline \multirow{2}{*}{$\begin{array}{c}\text { Communication } \\
\text { developmental quotient }\end{array}$} & -0.59 & -0.56 & -0.63 & -0.73 & 0.15 & -0.60 & -0.30 & 0.21 & -0.92 \\
\hline & 0.12 & 0.15 & 0.09 & 0.04 & 0.74 & 0.15 & 0.52 & 0.69 & $<0.01$ \\
\hline \multirow{2}{*}{$\begin{array}{l}\text { Motor developmental } \\
\text { quotient }\end{array}$} & -0.49 & -0.03 & -0.01 & -0.09 & 0.85 & -0.13 & 0.85 & 0.91 & -0.38 \\
\hline & 0.21 & 0.94 & 0.99 & 0.84 & 0.02 & 0.78 & 0.02 & 0.01 & 0.45 \\
\hline \multirow{2}{*}{$\begin{array}{l}\text { Cognitive developmental } \\
\text { quotient }\end{array}$} & -0.53 & -0.50 & -0.76 & -0.40 & -0.32 & -0.44 & -0.61 & 0.05 & -0.95 \\
\hline & 0.18 & 0.21 & 0.03 & 0.33 & 0.48 & 0.32 & 0.14 & 0.93 & $<0.01$ \\
\hline \multirow{2}{*}{$\begin{array}{l}\text { Total developmental } \\
\text { quotient }\end{array}$} & -0.62 & -0.53 & -0.53 & -0.67 & 0.26 & -0.54 & -0.19 & 0.29 & -0.91 \\
\hline & 0.10 & 0.18 & 0.17 & 0.07 & 0.57 & 0.21 & 0.68 & 0.58 & $<0.01$ \\
\hline
\end{tabular}

Adjusting for gestational age at time of MRI, $p$ value is based on a Bonferroni adjustment. Significance is $p<0.017$. 
a specific view to follow serially. Tilea et al have a sagittal vermis height growth curve for 26 to 40 weeks of gestation as measured by fetal ultrasound of normal healthy fetuses. ${ }^{46}$ Our values seem to correspond to this curve as well as other measurements obtained by ultrasound and MRI as their 50th percentile at 36 weeks was approximately $20 \mathrm{~mm}$ vermian height, as was ours on our normal controls. ${ }^{23,46}$

\section{Conclusion}

We are excited to present a few novel initial findings in our limited experience at this interim analysis in our longitudinal CHD fetal and neonatal brain develop study. We have demonstrated that CHD infants have delayed opercular closure, impaired cerebellar vermis growth, and that the cerebellar vermis growth correlates with several neurodevelopmental deficiencies.

Strengths of this study include that it is longitudinal, all measurements were done by one individual (and verified by another), the controls encompassed a large gestational age range, and that we were able to correlate anatomic measurements with neurodevelopment. Limitations include manual measurements, a small sample size without age-matched controls, difficulty in doing a timed analysis comparing two groups with only two time points (for some data points), and use of clinical controls. Also, head circumference was not available for comparison, and sex stratification analysis was not possible due to the small sample size.

Focusing further studies on specific anatomic brain regions in the CHD population, continuing to study patients to form a larger sample size, and developing targeted rehabilitative strategies to prevent such neurodevelopmental delays are our future goals.

\section{Conflict of Interest}

The authors declare no conflict of interest.

\section{Acknowledgments}

We would like to thank The Children's Heart Foundation, Children's Hospital of Los Angeles Clinical Trials Unit, and National Institutes of Health:

K23: NS063371 for their generous support. In addition, the University of Southern California Institute for Maternal-Fetal Health staff, Julia Castro, and the Children's Hospital Los Angeles Cardiothoracic Intensive Care Unit staff should be recognized for making sure the patients are enrolled and studied safely.

\section{References}

1 Mahle WT, Clancy RR, Moss EM, Gerdes M, Jobes DR, Wernovsky G. Neurodevelopmental outcome and lifestyle assessment in schoolaged and adolescent children with hypoplastic left heart syndrome. Pediatrics 2000;105(5):1082-1089

2 Marino BS, Lipkin PH, Newburger JW, et al; American Heart Association Congenital Heart Defects Committee, Council on
Cardiovascular Disease in the Young, Council on Cardiovascular Nursing, and Stroke Council. Neurodevelopmental outcomes in children with congenital heart disease: evaluation and management: a scientific statement from the American Heart Association. Circulation 2012;126(9):1143-1172

3 Licht DJ, Shera DM, Clancy RR, et al. Brain maturation is delayed in infants with complex congenital heart defects. J Thorac Cardiovasc Surg 2009;137(3):529-536, discussion 536-537

4 Limperopoulos C, Tworetzky W, McElhinney DB, et al. Brain volume and metabolism in fetuses with congenital heart disease: evaluation with quantitative magnetic resonance imaging and spectroscopy. Circulation 2010;121(1):26-33

5 Bellinger DC, Wypij D, duPlessis AJ, et al. Neurodevelopmental status at eight years in children with dextro-transposition of the great arteries: the Boston Circulatory Arrest Trial. J Thorac Cardiovasc Surg 2003;126(5):1385-1396

6 Hövels-Gürich HH, Konrad K, Skorzenski D, et al. Long-term neurodevelopmental outcome and exercise capacity after corrective surgery for tetralogy of Fallot or ventricular septal defect in infancy. Ann Thorac Surg 2006;81(3):958-966

7 Murdoch BE. The cerebellum and language: historical perspective and review. Cortex 2010;46(7):858-868

8 Leiner HC, Leiner AL, Dow RS. Reappraising the cerebellum: what does the hindbrain contribute to the forebrain? Behav Neurosci 1989;103(5):998-1008

9 Desmond JE, Gabrieli JDE, Glover GH. Dissociation of frontal and cerebellar activity in a cognitive task: evidence for a distinction between selection and search. Neuroimage 1998;7(4 Pt 1): 368-376

10 Tamburrini G, Frassanito P, Chieffo D, Massimi L, Caldarelli M, Di Rocco C. Cerebellar mutism. Childs Nerv Syst 2015;31(10): $1841-1851$

11 Allen G, McColl R, Barnard H, Ringe WK, Fleckenstein J, Cullum CM. Magnetic resonance imaging of cerebellar-prefrontal and cerebellar-parietal functional connectivity. Neuroimage 2005;28(1): 39-48

12 Wise RJ, Greene J, Büchel C, Scott SK. Brain regions involved in articulation. Lancet 1999;353(9158):1057-1061

13 Baillieux H, De Smet HJ, Paquier PF, De Deyn PP, Mariën P. Cerebellar neurocognition: insights into the bottom of the brain. Clin Neurol Neurosurg 2008;110(8):763-773

14 Chen CY, Zimmerman RA, Faro S, et al. MR of the cerebral operculum: topographic identification and measurement of interopercular distances in healthy infants and children. AJNR Am J Neuroradiol 1995;16(8):1677-1687

15 Larroche JC. Developmental pathology of the neonate. In: Development of the Central Nervous System. Amsterdam,. The Netherlands: Excerpta Medica; 1977:319-327

16 Tatum WO, Coker SB, Ghobrial M, Abd-Allah S. The open opercular sign: diagnosis and significance. Ann Neurol 1989;25(2):196-199

17 Chen CY, Zimmerman RA, Faro S, et al. MR of the cerebral operculum: abnormal opercular formation in infants and children. AJNR Am J Neuroradiol 1996;17(7):1303-1311

18 Sanz-Cortes M, Egaña-Ugrinovic G, Zupan R, Figueras F, Gratacos E. Brainstem and cerebellar differences and their association with neurobehavior in term small-for-gestational-age fetuses assessed by fetal MRI. Am J Obstet Gynecol 2014;210(5):452.e1-452.e8

19 Stoodley CJ. The cerebellum and cognition: evidence from functional imaging studies. Cerebellum 2012;11(2):352-365

20 Achiron R, Kivilevitch Z, Lipitz S, Gamzu R, Almog B, Zalel Y. Development of the human fetal pons: in utero ultrasonographic study. Ultrasound Obstet Gynecol 2004;24(5):506-510

21 Malinger G, Ginath S, Lerman-Sagie T, Watemberg N, Lev D, Glezerman M. The fetal cerebellar vermis: normal development as shown by transvaginal ultrasound. Prenat Diagn 2001;21(8): 687-692

22 Garel C. MRI of the Fetal Brain. Berlin, Germany: Springer-Verlag; 2004:151-175 
23 Triulzi F, Parazzini C, Righini A. MRI of fetal and neonatal cerebellar development. Semin Fetal Neonatal Med 2005;10(5):411-420

24 Scott JA, Hamzelou KS, Rajagopalan V, et al. 3D morphometric analysis of human fetal cerebellar development. Cerebellum 2012; 11(3):761-770

25 Yalin Imamoglu E, Gursoy T, Sancak S, Ovali F. Does being born small-for-gestational-age affect cerebellar size in neonates? J Matern Fetal Neonatal Med 2016;29(6):892-896

26 Nguyen The Tich S, Anderson PJ, Shimony JS, Hunt RW, Doyle LW, Inder TE. A novel quantitative simple brain metric using MR imaging for preterm infants. AJNR Am J Neuroradiol 2009;30(1): 125-131

27 Bertucci E, Gindes L, Mazza V, Re C, Lerner-Geva L, Achiron R. Vermian biometric parameters in the normal and abnormal fetal posterior fossa: three-dimensional sonographic study. J Ultrasound Med 2011;30(10):1403-1410

28 Bingham PM, Zimmerman RA, McDonald-McGinn D, Driscoll D, Emanuel BS, Zackai E. Enlarged sylvian fissures in infants with interstitial deletion of chromosome 22q11. Am J Med Genet 1997; 74(5):538-543

29 Mitnick RJ, Bello JA, Shprintzen RJ. Brain anomalies in velo-cardiofacial syndrome. Am J Med Genet 1994;54(2):100-106

30 Lynch DR, McDonald-McGinn DM, Zackai EH, et al. Cerebellar atrophy in a patient with velocardiofacial syndrome. J Med Genet 1995;32(7):561-563

31 Mahle WT, Tavani F, Zimmerman RA, et al. An MRI study of neurological injury before and after congenital heart surgery. Circulation 2002;106(12, Suppl 1):I109-I114

32 Glauser TA, Rorke LB, Weinberg PM, Clancy RR. Congenital brain anomalies associated with the hypoplastic left heart syndrome. Pediatrics 1990;85(6):984-990

33 Khalil A, Suff N, Thilaganathan B, Hurrell A, Cooper D, Carvalho JS. Brain abnormalities and neurodevelopmental delay in congenital heart disease: systematic review and meta-analysis. Ultrasound Obstet Gynecol 2014;43(1):14-24

34 Ortinau C, Alexopoulos D, Dierker D, Van Essen D, Beca J, Inder T. Cortical folding is altered before surgery in infants with congenital heart disease. J Pediatr 2013;163(5):1507-1510
35 Clouchoux C, du Plessis AJ, Bouyssi-Kobar M, et al. Delayed cortical development in fetuses with complex congenital heart disease. Cereb Cortex 2013;23(12):2932-2943

36 Farzan F, Pascual-Leone A, Schmahmann JD, Halko M. Enhancing the temporal complexity of distributed brain networks with patterned cerebellar stimulation. Sci Rep 2016 6(6):23599

37 De Smet HJ, Paquier P, Verhoeven J, Mariën P. The cerebellum: its role in language and related cognitive and affective functions. Brain Lang 2013;127(3):334-342

38 Fabbro F, Moretti R, Bava A. Language impairments in patients with cerebellar lesions. J Neurolinguist 2000;13(2):173-188

39 Gadgil N, Hansen D, Barry J, Chang R, Lam S. Posterior fossa syndrome in children following tumor resection: knowledge update. Surg Neurol Int 2016;7(6, Suppl 6):S179-S183

40 Puget S, Boddaert N, Viguier D, et al. Injuries to inferior vermis and dentate nuclei predict poor neurological and neuropsychological outcome in children with malignant posterior fossa tumors. Cancer 2009;115(6):1338-1347

41 Brossard-Racine M, du Plessis AJ, Vezina G, et al. Prevalence and spectrum of in utero structural brain abnormalities in fetuses with complex congenital heart disease. AJNR Am J Neuroradiol 2014; 35(8):1593-1599

42 Borzage M, Blüml S, Seri I. Equations to describe brain size across the continuum of human lifespan. Brain Struct Funct 2014;219(1): $141-150$

43 Rajagopalan V, Scott J, Habas PA, et al. Local tissue growth patterns underlying normal fetal human brain gyrification quantified in utero. J Neurosci 2011;31(8):2878-2887

44 Li G, Nie J, Wang L, et al. Mapping longitudinal hemispheric structural asymmetries of the human cerebral cortex from birth to 2 years of age. Cereb Cortex 2014;24(5):1289-1300

45 Brouwer MJ, de Vries LS, Groenendaal F, et al. New reference values for the neonatal cerebral ventricles. Radiology 2012;262(1): 224-233

46 Tilea B, Alberti C, Adamsbaum C, et al. Cerebral biometry in fetal magnetic resonance imaging: new reference data. Ultrasound Obstet Gynecol 2009;33(2):173-181 


\section{Appendix}

Appendix: Correlation of Brain Measurements and Battelle Scores (All Patients)

\begin{tabular}{|c|c|c|c|c|c|c|c|c|c|c|c|c|c|c|c|c|}
\hline \multirow[b]{2}{*}{$\begin{array}{c}\text { Score } \\
\text { (Correlation, p- } \\
\text { value) }\end{array}$} & \multicolumn{5}{|c|}{ Fetal } & \multicolumn{8}{|c|}{ Pre Op } & \multicolumn{3}{|c|}{ Post-Op } \\
\hline & $\begin{array}{c}\mathrm{L} \\
\text { Opercul } \\
\text { um } \\
\text { Length }\end{array}$ & $\begin{array}{c}\mathrm{R} \\
\text { Cerebel } \\
\text { ar } \\
\text { Hemisph } \\
\text { ere }\end{array}$ & $\begin{array}{c}\text { Bone } \\
\text { II Bipariet } \\
\text { al } \\
\text { h Diamet } \\
\text { er }\end{array}$ & $\begin{array}{l}\text { Lentric } \\
\text { le }\end{array}$ & $\begin{array}{c}\mathrm{R} \\
\text { cVentric } \\
\text { le }\end{array}$ & $\begin{array}{c}\mathrm{L} \\
\text { Opercul } \\
\text { um } \\
\text { Inside } \\
\text { W }\end{array}$ & $\begin{array}{c}\mathrm{L} \\
\text { Opercul } \\
\text { um } \\
\text { Outside } \\
\text { W }\end{array}$ & $\begin{array}{l}\text { L } \\
\text { Opercul } \\
\text { um } \\
\text { Length }\end{array}$ & $\begin{array}{c}\text { R } \\
\text { Opercul } \\
\text { um } \\
\text { Length }\end{array}$ & $\begin{array}{c}\text { Brain } \\
\text { Biparie } \\
\text { tal } \\
\text { Diamet } \\
\text { er }\end{array}$ & $\begin{array}{c}\text { Bone } \\
\text { Biparie } \\
\text { tal } \\
\text { Diamet } \\
\text { er }\end{array}$ & $\begin{array}{c}\text { Ventric } \\
t \quad l e\end{array}$ & $\begin{array}{c}\mathrm{R} \\
\text { cVentric } \\
\text { le }\end{array}$ & $\begin{array}{l}\text { Cerebell } \\
\text { um Inf } \\
\text { Vermis } \\
\text { Width }\end{array}$ & $\begin{array}{c}\text { II } \\
\text { Ventric } \\
\text { e }\end{array}$ & $\begin{array}{c}\mathrm{R} \\
\mathrm{l} \text { le } \\
\mathrm{le} \text { tric }\end{array}$ \\
\hline Self Care & $\begin{array}{r}-0.67 \\
0.03\end{array}$ & $\begin{array}{c}-0.58 \\
0.08\end{array}$ & $\begin{array}{c}-0.66 \\
0.04\end{array}$ & $\begin{array}{l}-0.80 \\
<0.01\end{array}$ & $\begin{array}{l}-0.77 \\
1<0.01\end{array}$ & $\begin{array}{l}-0.83 \\
<0.01\end{array}$ & $\begin{array}{c}-0.74 \\
0.02\end{array}$ & $\begin{array}{r}-0.61 \\
0.08\end{array}$ & $\begin{array}{l}-0.80 \\
0.01\end{array}$ & $\begin{array}{r}-0.73 \\
0.03\end{array}$ & $\begin{array}{l}-0.83 \\
<0.01\end{array}$ & $\begin{array}{l}-0.77 \\
0.02\end{array}$ & $\begin{array}{c}-0.75 \\
0.02\end{array}$ & $\begin{array}{c}-0.63 \\
0.13\end{array}$ & $\begin{array}{r}-0.57 \\
0.18\end{array}$ & $\begin{array}{r}-0.57 \\
0.18\end{array}$ \\
\hline Peer Interaction & $\begin{array}{l}0.97 \\
0.02\end{array}$ & $\begin{array}{l}0.22 \\
0.78\end{array}$ & $\begin{array}{l}0.98 \\
0.02\end{array}$ & $\begin{array}{l}0.78 \\
0.22\end{array}$ & $\begin{array}{l}0.22 \\
0.78\end{array}$ & $\begin{array}{l}0.67 \\
0.22\end{array}$ & $\begin{array}{l}0.82 \\
0.09\end{array}$ & $\begin{array}{c}0.97 \\
<0.01\end{array}$ & $\begin{array}{l}0.82 \\
0.09\end{array}$ & $\begin{array}{l}0.15 \\
0.80\end{array}$ & $\begin{array}{l}0.67 \\
0.22\end{array}$ & $\begin{array}{l}0.76 \\
0.13\end{array}$ & $\begin{array}{l}0.82 \\
0.09\end{array}$ & $\begin{array}{c}-0.82 \\
0.18\end{array}$ & $\begin{array}{l}0.32 \\
0.68\end{array}$ & $\begin{array}{r}-0.32 \\
0.68\end{array}$ \\
\hline $\begin{array}{l}\text { Self Concept and } \\
\text { Social Role }\end{array}$ & $\begin{array}{r}-0.50 \\
0.15\end{array}$ & $\begin{array}{c}-0.75 \\
0.01\end{array}$ & $\begin{array}{l}-0.92 \\
<0.01\end{array}$ & $\begin{array}{c}-0.74 \\
0.01\end{array}$ & $\begin{array}{c}-0.73 \\
0.02\end{array}$ & $\begin{array}{r}-0.75 \\
0.02\end{array}$ & $\begin{array}{c}-0.46 \\
0.21\end{array}$ & $\begin{array}{l}0.04 \\
0.92\end{array}$ & $\begin{array}{c}-0.77 \\
0.02\end{array}$ & $\begin{array}{c}-0.70 \\
0.04\end{array}$ & $\begin{array}{c}-0.73 \\
0.03\end{array}$ & $\begin{array}{r}-0.41 \\
0.27\end{array}$ & $\begin{array}{c}-0.66 \\
0.06\end{array}$ & $\begin{array}{c}-0.81 \\
0.03\end{array}$ & $\begin{array}{r}-0.47 \\
0.29\end{array}$ & $\begin{array}{r}-0.50 \\
0.25\end{array}$ \\
\hline $\begin{array}{l}\text { Receptive } \\
\text { Communication }\end{array}$ & $\begin{array}{r}-0.30 \\
0.40\end{array}$ & $\begin{array}{c}-0.42 \\
0.23\end{array}$ & $\begin{array}{c}-0.54 \\
0.11\end{array}$ & $\begin{array}{c}-0.30 \\
0.40\end{array}$ & $\begin{array}{c}-0.38 \\
0.28\end{array}$ & $\begin{array}{c}-0.59 \\
0.10\end{array}$ & $\begin{array}{r}-0.34 \\
0.37\end{array}$ & $\begin{array}{r}-0.23 \\
0.56\end{array}$ & $\begin{array}{r}-0.30 \\
0.43\end{array}$ & $\begin{array}{c}-0.44 \\
0.23\end{array}$ & $\begin{array}{c}-0.40 \\
0.30\end{array}$ & $\begin{array}{r}-0.40 \\
0.28\end{array}$ & $\begin{array}{c}-0.17 \\
0.66\end{array}$ & $\begin{array}{l}-0.86 \\
0.01\end{array}$ & $\begin{array}{c}-0.80 \\
0.03\end{array}$ & $\begin{array}{r}-0.72 \\
0.07\end{array}$ \\
\hline $\begin{array}{l}\text { Expressive } \\
\text { Communication }\end{array}$ & $\begin{array}{c}-0.58 \\
0.08\end{array}$ & $\begin{array}{c}-0.46 \\
0.18\end{array}$ & $\begin{array}{c}-0.58 \\
0.08\end{array}$ & $\begin{array}{l}-0.78 \\
<0.01\end{array}$ & $\begin{array}{cc}-0.73 \\
1 & 0.02\end{array}$ & $\begin{array}{c}-0.73 \\
0.02\end{array}$ & $\begin{array}{c}-0.76 \\
0.02\end{array}$ & $\begin{array}{c}-0.08 \\
0.83\end{array}$ & $\begin{array}{l}-0.83 \\
<0.01\end{array}$ & $\begin{array}{c}-0.63 \\
0.07\end{array}$ & $\begin{array}{c}-0.79 \\
0.01\end{array}$ & $\begin{array}{r}-0.61 \\
0.08\end{array}$ & $\begin{array}{l}-0.80 \\
<0.01\end{array}$ & $\begin{array}{r}-0.80 \\
0.03\end{array}$ & $\begin{array}{c}-0.86 \\
0.01\end{array}$ & $\begin{array}{r}-0.79 \\
0.04\end{array}$ \\
\hline $\begin{array}{l}\text { Attention and } \\
\text { Memory }\end{array}$ & $\begin{array}{r}-0.14 \\
0.69\end{array}$ & $\begin{array}{c}-0.73 \\
0.02\end{array}$ & $\begin{array}{l}-0.81 \\
<0.01\end{array}$ & $\begin{array}{c}-0.58 \\
0.08\end{array}$ & $\begin{array}{c}-0.64 \\
0.05\end{array}$ & $\begin{array}{c}-0.64 \\
0.06\end{array}$ & $\begin{array}{r}-0.40 \\
0.29\end{array}$ & $\begin{array}{c}-0.05 \\
0.90\end{array}$ & $\begin{array}{r}-0.40 \\
0.29\end{array}$ & $\begin{array}{r}-0.47 \\
0.20\end{array}$ & $\begin{array}{c}-0.38 \\
0.31\end{array}$ & $\begin{array}{r}-0.53 \\
0.14\end{array}$ & $\begin{array}{c}-0.41 \\
0.27\end{array}$ & $\begin{array}{l}-0.92 \\
<0.01\end{array}$ & $\begin{array}{r}-0.75 \\
0.05\end{array}$ & $\begin{array}{l}-0.85 \\
0.02\end{array}$ \\
\hline $\begin{array}{l}\text { Adaptive } \\
\text { Developmental } \\
\text { Quotient }\end{array}$ & $\begin{array}{r}-0.63 \\
0.05\end{array}$ & $\begin{array}{c}-0.57 \\
0.09\end{array}$ & $\begin{array}{r}-0.55 \\
0.10\end{array}$ & $\begin{array}{c}-0.65 \\
0.04\end{array}$ & $\begin{array}{c}-0.73 \\
0.02\end{array}$ & $\begin{array}{c}-0.73 \\
0.03\end{array}$ & $\begin{array}{c}-0.60 \\
0.09\end{array}$ & $\begin{array}{c}-0.64 \\
0.07\end{array}$ & $\begin{array}{c}-0.64 \\
0.06\end{array}$ & $\begin{array}{l}-0.81 \\
<0.01\end{array}$ & $\begin{array}{c}-0.77 \\
0.01\end{array}$ & $\begin{array}{r}-0.74 \\
0.02\end{array}$ & $\begin{array}{r}-0.62 \\
0.07\end{array}$ & $\begin{array}{c}-0.69 \\
0.09\end{array}$ & $\begin{array}{c}-0.67 \\
0.10\end{array}$ & $\begin{array}{c}-0.66 \\
0.11\end{array}$ \\
\hline $\begin{array}{l}\text { Communication } \\
\text { Developmental } \\
\text { Quotient }\end{array}$ & $\begin{array}{c}-0.58 \\
0.08\end{array}$ & $\begin{array}{c}-0.53 \\
0.12\end{array}$ & $\begin{array}{r}-0.64 \\
0.05\end{array}$ & $\begin{array}{c}-0.74 \\
0.02\end{array}$ & $\begin{array}{c}-0.72 \\
0.02\end{array}$ & $\begin{array}{l}-0.79 \\
0.01\end{array}$ & $\begin{array}{r}-0.73 \\
0.02\end{array}$ & $\begin{array}{r}-0.23 \\
0.55\end{array}$ & $\begin{array}{c}-0.77 \\
0.02\end{array}$ & $\begin{array}{c}-0.66 \\
0.05\end{array}$ & $\begin{array}{c}-0.78 \\
0.01\end{array}$ & $\begin{array}{r}-0.63 \\
0.07\end{array}$ & $\begin{array}{c}-0.70 \\
0.03\end{array}$ & $\begin{array}{r}-0.82 \\
0.02\end{array}$ & $\begin{array}{c}-0.86 \\
0.01\end{array}$ & $\begin{array}{l}0.81 \\
0.03\end{array}$ \\
\hline $\begin{array}{l}\text { Motor } \\
\text { Developmental } \\
\text { Quotient }\end{array}$ & $\begin{array}{c}-0.74 \\
0.01\end{array}$ & $\begin{array}{c}-0.05 \\
0.89\end{array}$ & $\begin{array}{c}-0.10 \\
0.78\end{array}$ & $\begin{array}{r}-0.27 \\
0.45\end{array}$ & $\begin{array}{c}-0.32 \\
0.37\end{array}$ & $\begin{array}{c}-0.33 \\
0.38\end{array}$ & $\begin{array}{c}-0.36 \\
0.34\end{array}$ & $\begin{array}{c}-0.15 \\
0.71\end{array}$ & $\begin{array}{r}-0.30 \\
0.43\end{array}$ & $\begin{array}{c}-0.18 \\
0.64\end{array}$ & $\begin{array}{c}-0.43 \\
0.25\end{array}$ & $\begin{array}{l}0.05 \\
0.90\end{array}$ & $\begin{array}{c}-0.08 \\
0.84\end{array}$ & $\begin{array}{c}-0.33 \\
0.48\end{array}$ & $\begin{array}{c}-0.45 \\
0.31\end{array}$ & $\begin{array}{r}-0.33 \\
0.47\end{array}$ \\
\hline $\begin{array}{l}\text { Cognitive } \\
\text { Developmental } \\
\text { Quotient }\end{array}$ & $\begin{array}{r}-0.37 \\
0.29\end{array}$ & $\begin{array}{c}-0.58 \\
0.08\end{array}$ & $\begin{array}{c}-0.68 \\
0.03\end{array}$ & $\begin{array}{c}-0.42 \\
0.23\end{array}$ & $\begin{array}{c}-0.55 \\
0.10\end{array}$ & $\begin{array}{c}-0.59 \\
0.09\end{array}$ & $\begin{array}{r}-0.20 \\
0.61\end{array}$ & $\begin{array}{r}-0.23 \\
0.55\end{array}$ & $\begin{array}{r}-0.25 \\
0.52\end{array}$ & $\begin{array}{l}0.35 \\
0.36\end{array}$ & $\begin{array}{c}-0.26 \\
0.49\end{array}$ & $\begin{array}{c}-0.39 \\
0.30\end{array}$ & $\begin{array}{c}-0.10 \\
0.80\end{array}$ & $\begin{array}{l}-0.91 \\
<0.01\end{array}$ & $\begin{array}{r}-0.75 \\
0.05\end{array}$ & $\begin{array}{r}-0.71 \\
0.08\end{array}$ \\
\hline $\begin{array}{l}\text { Total } \\
\text { Developmental } \\
\text { Quotient }\end{array}$ & $\begin{array}{r}-0.55 \\
0.10\end{array}$ & $\begin{array}{c}-0.42 \\
0.22\end{array}$ & $\begin{array}{c}-0.48 \\
0.16\end{array}$ & $\begin{array}{r}-0.65 \\
0.04\end{array}$ & $\begin{array}{r}-0.72 \\
0.02\end{array}$ & $\begin{array}{c}-0.76 \\
0.02\end{array}$ & $\begin{array}{r}-0.72 \\
0.03\end{array}$ & $\begin{array}{c}-0.14 \\
0.71\end{array}$ & $\begin{array}{r}-0.65 \\
0.06\end{array}$ & $\begin{array}{c}-0.58 \\
0.10\end{array}$ & $\begin{array}{c}-0.69 \\
0.04\end{array}$ & $\begin{array}{r}-0.54 \\
0.13\end{array}$ & $\begin{array}{r}-0.61 \\
0.08\end{array}$ & $\begin{array}{r}-0.81 \\
0.03\end{array}$ & $\begin{array}{c}-0.87 \\
0.01\end{array}$ & $\begin{array}{r}-0.80 \\
0.03\end{array}$ \\
\hline
\end{tabular}

Adjusting for Gestational Age at time of MRI, p-value is based on a Bonferroni Adjustment. Significance is $<0.017$ 